\title{
Uma leitura psicanalítica da vivência da maternidade nos casos de aborto e prematuridade
}

\author{
Psychoanalytical perspective of motherhood experiences in abortion and premature \\ birth cases \\ Una lectura psicoanalítica de la experiencia de la maternidad en casos de aborto y \\ prematuridad \\ Mychele Capellini Moris Taguchi ${ }^{1}$ \\ Danielle Abdel Massih Pio ${ }^{2}$ \\ Programa de Aprimoramento Profissional em Psicologia Hospitalar \\ Faculdade de Medicina de Marília (FAMEMA) - Marília/SP.
}

\begin{abstract}
Resumo
A maternidade é um momento em que a mulher passa por transformações orgânicas e psíquicas. Por vezes a vivência é assustadora, podendo a gestante ter complicações e evoluir para patologias e sintomas chegando, muitas vezes, a experimentar situações de aborto ou prematuridade. Utilizando as bases BVS, LILACS, SCIELO, MEDLINE e BIREME, foram encontradas publicações no período de 1980 a 2012. Sustentados por casos atendidos durante o Programa de Aprimoramento Profissional em Psicologia Hospitalar da Faculdade de Medicina de Marília/SP, os autores fazem uma leitura psicanalítica hipotetizando que a preponderância de ansiedades persecutórias podem ser determinantes para a evolução das gestações para situações de aborto e prematuridade. Conclui-se que, em geral, a revisão bibliográfica reforça a necessidade de atenção a essas gestantes no intuito de auxiliá-las a vivenciar tal situação de forma menos atemorizante, com direcionamento a uma prevenção em saúde mental e, de maneira geral, a um cuidado em saúde.
\end{abstract}

Palavras-chave: Maternidade; Aborto; Prematuridade; Fantasias psíquicas; Ansiedade.

\begin{abstract}
Motherhood is a period in that woman's life goes through organic and psychological transformations. Sometimes this experience is frightening, especially when the pregnant can have complications and develop symptoms and diseases often leading to abortion or premature birth situations. Based on BVS, LILACS, SCIELO, MEDLINE and BIREME we found publications from 1980 to 2012 on this subject. A psychoanalytic reading is made by several authors' hypothesis that the preponderance of persecutory anxieties mighty be decisive for the evolution from pregnancies to abortion and prematurity situations indicated by cases seen during studies at a Medicine College in Marília/SP concerning the Professional Development of Health Psychology. As conclusion, we affirm the review emphasizes that attention should be directed to these pregnant women in order to help them to experience such a situation in a less scary manner, providing them with preventive measures including mental and health care in general.

Key-words: Motherhood; Abortion; Prematurity; Psychic fantasies; Anxiety.
\end{abstract}

\begin{abstract}
Resumen
La maternidad es un momento en el cual la mujer sufre transformaciones orgánicas y psicológicas. A veces, dicha experiencia es asustadora y angustiante. Las mujeres embarazadas pueden incluso tener complicaciones que se convierten en síntomas y enfermedades que, a menudo, conllevan a situaciones de aborto o parto prematuro. Utilizándose las bases BVS, SciELO, LILACS, MEDLINE y BIREME, fueron halladas publicaciones, entre 1980 y el 2012. A partir de casos atendidos durante el Programa de Mejoría Profesional en Psicología del Hospital de la Facultad de Medicina de Marília/SP, los autores realizan una lectura psicoanalítica bajo la hipótesis de que la preponderancia de las ansiedades persecutorias puede ser decisiva para la evolución de los embarazos, en situaciones de aborto y nacimientos prematuros. Llegamos a la conclusión de que, en general, la revisión bibliográfica pone en relieve la necesidad de poner más atención en estas mujeres encintas, con la finalidad de ayudarles a sobrellevar ésa situación de manera menos amedrentadora hacia la prevención de la salud mental y, al todo, una salud cuidada con la debida atención.

Palabras-clave: Maternidad; Aborto; Prematuridad; Fantasías psíquicas; Ansiedad.
\end{abstract}

\section{Introdução}

Endereço 1: Al. Ezequiel Mantoanelli, 618. Lote 02 Quadra F, CEP: $13.340-350$ Indaiatuba-SP.

Endereço 2: Avenida Brigadeiro Eduardo Gomes, 3551, casa F12, CEP: 17.514-000 Marília-SP.

\section{Aspectos históricos da maternidade}

A maternidade nem sempre foi considerada sinônimo de amor, dedicação e cuidados maternos. A exaltação ao amor materno é fato relativamente recente dentro da história da civilização ocidental, constituindo-se em um mito 
construído pelos discursos filosófico, médico e político a partir do século XVIII (Badinter, 1987; Moura \& Araújo, 2004).

Maldonado (1980) faz uma retrospectiva da construção sócio-histórica relacionada à maternidade e relata que no início do século XVI, na Europa, era costume da sociedade delegar as funções de cuidado, higiene, carinho às chamadas amas de leite, que amamentavam e cuidavam das crianças em seus primeiros anos de vida. Essas pessoas chegavam a abandonar seus próprios filhos para cuidar de crianças abastadas a elas destinadas. Esse processo culminou na criação de instituições, no início do século XVII, que eram imbuídas de receber e cuidar de crianças em situações de abandono, características desta época.

No Brasil, mais especificamente no Rio de Janeiro, a autora cita a Fundação Romão Duarte (1738) a qual recebia as crianças deixadas nas rodas que eram, geralmente, filhos ilegítimos que poderiam manchar a honra da família colonial.

$\mathrm{Na}$ Idade Média, as crianças permaneciam vinculadas às suas famílias por pouco tempo, entre os sete e os dez anos, quando eram entregues a outras famílias para receberem instrução. A criança passava a conviver com os adultos, desde a sua mais tenra idade, passando por aprendizagens que a levariam a exercer atividades de prática dos adultos. (Ariés, 1981; Badinter, 1987).

Esses fatos históricos sugerem que, até o final do século XVIII, o que predominava era uma conduta materna procriativa com relação à criança, de pouca percepção social e emocional da infância. Dadas as circunstâncias do momento histórico, ao que parece, o simbolismo da maternidade e infância era essencialmente biológico e mercantilista (Ariés, 1981).

Já no século seguinte, a presença da mãe foi ressaltada num contexto religioso, onde a esta era designada a transmissão do conhecimento e da instrução religiosa. No final do século XVIII, com a exaltação do amor por filósofos, médicos, políticos, a função materna começou a adquirir outras funções, incluindo maior participação e responsabilidade no cuidado aos filhos (Maldonado, 1980).

Com o início do século XIX e, portanto, com o advento da industrialização, aos homens era delegada a função de trabalhar fora de casa e às mulheres ficava o convívio do lar e a educação dos filhos. Isso proporcionava um maior contato entre mães e filhos, com a possibilidade de maior percepção das necessidades existentes na relação (Maldonado, 1981).

No século XX, a mulher ocupa um lugar central na família, função esta influenciada pelos discursos médicos e psicanalíticos. Há um avanço relacional mãe-filho, no que concerne ao estabelecimento de vínculo e afeto, com a importância dada ao convívio e à disponibilidade ao cuidado de uma relação (Maldonado, 1981).

Freud (1976) discorrendo sobre o determinismo psíquico postulou, no entanto, que todas as ações e reações humanas estão fundamentadas em um componente mental que é inconsciente, porém que de alguma forma tem sua expressão. Ao discorrer sobre atos falhos e atos causais coloca que "os fenômenos podem ser reportados a um material psíquico incompletamente suprimido, o qual, apesar de repelido pela consciência, ainda sim não teve toda sua capacidade de se exprimir" (Freud, 1976, p.332).

Neste sentido, como já observado por alguns autores, a vivência da maternidade necessita ser compreendida em suas dimensões psíquicas existentes para o alcance de uma experiência mais ampla e integrada acerca da possibilidade de sua constituição ou da relação vincular. (Piccinini, Gomes, Nardi \& Lopes, 2008; Soifer, 1980; Maldonado, 2000; Stellin, Monteiro, Albuquerque \& Marques, 2011).

\section{Maternidade e Psicanálise}

A maternidade é um momento intenso para as mulheres, em que há uma alteração na dinâmica psíquica da gestante visto alterações biológicas, somáticas, psicológicas e sociais, características do período. Pode ser vista como um período de crise por onde perpassam pontos conflitivos decisórios, de crescimento emocional, que podem determinar o estado de saúde ou de doença mental da mulher e da família que a vivencia. A maternidade mostra-se associada às matrizes vinculares da mulher e à alteração significativa com os padrões interacionais junto à família de origem. (Maldonado, 1992; Piccinini et al., 2008).

Esse período conflitivo mencionado estaria diretamente relacionado ao conceito de crise de Caplan (1963 como citado em Maldonado, 1985, p.19), definido como um momento de perturbação temporária, de enfraquecimento das funções egóicas que impede a pessoa de se utilizar de métodos habituais de conduta, a fim de solucionar suas questões emergentes.

As soluções encontradas podem ser saudáveis, momento em que o indivíduo procura outras respostas antes desconhecidas com êxito ou, levar a pessoa ao adoecimento, ao não solucionar seus conflitos gerando um nível maior de desorganização. A crise que culmina em uma desorganização, no caso da maternidade, seria o não poder usufruir desse momento com satisfação, alegria, altruísmo e sim com ansiedade prolongada, tristeza e angústia exacerbadas (Maldonado, 1981).

No que tange à revivescências infantis, o período da concepção e o consequente desenvolvimento dos filhos remetem a mulher e o homem a reviver suas próprias histórias como filhos, ou seja, perpassam momentos conscientes e inconscientes do eixo relacional os quais vivenciaram com seus pais. Isso geralmente leva a uma nova definição de papéis trazendo à tona, muitas vezes, conflitos antigos de relacionamento. (Ferrari, Piccinini \& Lopes, 2006; Maldonado, 1922).

Quando uma mulher se torna mãe ela revive a situação de deixar de ser somente filha para agora ser filha e mãe. Nesse sentido, a mulher passa por uma dupla identificação a nível consciente e inconsciente, ou seja, "fazem uma revisão do modelo parental e do processo educacional ao qual foram submetidos e, além disso, identificam-se com o bebê, gestando expectativas e anseios com relação ao próprio papel de pais e as características da criança" (Maldonado, 1992, p. 208).

Essa dupla identificação tem no seu bojo aspectos regressivos refletidos na relação que a mulher estabelece com seus afins. Esses aspectos regressivos podem ser positivos, buscando carinho, proteção e cuidados, principalmente com uma figura feminina em que a gestante pode se espelhar para expressar e fortalecer capacidades e sentimentos maternos ou negativos, desenvolvendo reações como ansiedades e angústias intensificadas. (Lopes, Prochnow \& Piccinini, 2010; Maldonado, 2010).

Tanto as gestações planejadas como as não planejadas carregam consigo perspectivas de mudanças na família, tanto estruturais, como financeiras, interpessoais ou emocionais. Essas mudanças envolvem ganhos e perdas, 
fazem com que exista uma exigência de esforços de readaptação familiar que, geralmente, causam desconforto, tensão e sentimentos de ambivalência afetiva. A forma de manejar esses sentimentos é um dos fatores que será determinante na gratificação ou frustração da gestante com relação ao seu momento e ao bebê (Freire \& Chaterlard, 2009; Maldonado, 1992).

Maldonado (1981) amplia ao falar sobre uma oscilação entre desejar e não desejar um filho. Não há gravidez totalmente aceita ou totalmente rejeitada. A esse respeito, Soifer (1980) pontua que a relação com o bebê, desde o início da gestação, é permeada de incertezas e sentimentos ambivalentes de amor e rejeição, cuja base encontra-se nas vivências persecutórias e terroríficas experienciadas pela mãe durante o conflito edípico.

Klein (1991) coloca que o conflito no bebê, entre o que chama de seio gratificante/bom e seio frustrador/mau, remete-o à possibilidade de enfrentamento e superação, movimento fundamental na criatividade do indivíduo. Esse movimento de ambivalência e da possibilidade de enfrentamento é revivido durante o período gestacional.

Assim, para que a mulher consiga acolher o filho e que esse filho deseje viver, há a necessidade da busca em si do desejo, de uma confiança que lhe traga segurança suficiente para que, mesmo mergulhada nessas mudanças e transformações, possa ser dimensão alteritária para seu bebê num movimento instaurador de vida, podendo atender às necessidades específicas de cada momento de seu desenvolvimento - gestação, puerpério e crescimento (Catão, 2004; Freire \& Chatelard, 2008; Maldonado, 1992). Zalcberg (2003) refere que o que impera para a criança é o poder materno: suas respostas constituem leis, suas demandas são mandamentos e seus desejos são desígnios. Quanto mais uma criança viver sob a chancela do poder de doação materno, mais ela é vivida como potência de dar vida ou potência de dar a morte.

Exercer a maternidade, portanto, exige da mulher recursos psíquicos específicos e nesse sentido, atender as necessidades de cuidado e proteção materna é essencial para que mulher possa vivenciar esse momento da forma mais saudável. (Stellin et al., 2011). Porém, se sentir protegida carrega em si o registro de ter se sentido em algum momento protegida, cuidada, ou seja, remete a qualidade de relação que vivenciou durante sua infância, ao bom objeto internalizado, como postula Melanie Klein (1996).

O bom objeto internalizado permite que o ser humano se desenvolva com aspectos que a remetam à confiança em si, segurança, capacidade de amar, de cuidar e proteger. Dessa forma, as relações a que essa mãe quando bebê estabeleceu com seus parentais, reflete sua maneira de acolher, cuidar e de sustentar o filho que gera (Klein, 1996).

Klein (1991) acrescenta que o estado pré-natal (gestação) para o feto the implica um sentimento de unidade e segurança, porém o quanto está livre de perturbações dependerá necessariamente das condições psicológicas e físicas da mãe.

O estudo tratará da maternidade, portanto, com um enfoque psicanalítico sobre as perdas gestacionais, abordando os aspectos destrutivos inconscientes da relação da mãe com seu feto/bebê, a qual em um determinado momento vivencia situações de aborto ou prematuridade do filho.

\section{Método}

O desejo de compreender psicanaliticamente os conteúdos inconscientes emergidos de mulheres que haviam passado por situações de aborto ou prematuridade do filho surgiu dos atendimentos psicológicos realizados durante $o$ aprimoramento profissional em psicologia hospitalar, no período de permanência nas enfermarias e ambulatórios de ginecologia e obstetrícia da Faculdade de Medicina de Marília/SP (FAMEMA). Fazia-se necessário, para o entendimento e intervenção psicológica, uma compreensão do sofrimento manifesto e, especialmente, latente dessas mulheres.

As pesquisas foram feitas utilizando-se as bases de dados da Biblioteca Virtual de Saúde (BVS), Literatura Latino-Americana e do Caribe em Ciências da Saúde (LILACS), Scientific Eletronic Library Online (SCIELO), Medical Literature Analysis and Retrieval System Online (MEDLINE) e Centro Latino-Americana e do Caribe de Informação em Ciências da Saúde (BIREME). Foram incluídas publicações no período de 1980 a 2012. Utilizaram-se descritores como maternidade, psicanálise, instinto de morte, aborto e prematuridade.

\section{Discussão}

\section{Fantasias persecutórias na gestação}

As gestantes do Hospital Materno Infantil do Hospital das Clínicas da Faculdade de Medicina de Marília (FAMEMA) geralmente estão internadas devido a alguma complicação que pode colocar em risco sua gestação. Assim, nota-se que as patologias mais frequentes são hipertensão gestacional, hipertensão crônica, diabetes melitus, diabetes gestacional, além de sintomas como hemorragias, amniorrexe, hiperemese, entre outras complicações, em que se sugere a internação para repouso e auxílio medicamentoso, para que a gestação possa seguir seu curso.

Muitas vezes, os profissionais utilizam a expressão "segurar a gestação" ou "segurar o feto" para as condutas terapêuticas adotadas frente à possibilidade de nascimento prematuro ou como medida evitativa de aborto, sugerindo a necessidade de apoio, suporte externo para que as gestantes tenham a possibilidade de chegar ao fim da gestação com êxito.

Ao refletir sobre essas reações na gestação durante os atendimentos realizados, notou-se a predominância de várias fantasias relacionadas à morte, perdas, associadas geralmente a características imaturas de personalidades e histórico de vida permeado de conflitos, dificuldades. As falas predominantes, geralmente eram preocupação com o futuro da gestação, insatisfação com a gestação em função das reações que a provocavam e insatisfação com as internações frequentes.

Muitas apresentavam reações defensivas como negação, projeção, formação reativa e traziam sensação de se sentirem sós, desamparadas pela família, pelos cônjuges, além do relato de sentimentos, muitas vezes, contraditórios como tristeza, alívio, culpa, medo, vivenciando momentos de intensas reações emocionais e alternância de sentimentos que pareciam funcionar como nuvens que ofuscavam emergência do desejo.

Soifer (1980) refere que a suspeita da gravidez já desperta fantasias e que, desde o início, a mulher vivencia situações ansiógenas, podendo desencadear sintomatologias físicas e mentais. Alguns sintomas e fantasias são bastante naturais, porém a exacerbação destas e a vivência de forma predominantemente persecutória é que gera preocupação e exige cuidados mais intensos. 
Alguns sintomas decorrentes de vivências persecutórias inconscientes, experimentadas frequentemente pelas gestantes no início da gestação, são as náuseas e vômitos que, segundo Soifer (1980), demonstram ser mecanismos de vazão à ansiedade gerada pela dúvida de estar ou não grávida. Essa ansiedade, derivada da incerteza, faz alusão ao conflito da ambivalência, de desejar e não-desejar, de amar-odiar.

Langer (1986) coloca que a expulsão através do vômito realiza-se por diversas razões, dentre elas, por chocar com um desejo de prosseguir com a gravidez, pois se assim não fosse o "inconsciente não se conformaria com um intento de interrupção da gravidez que não tem mais valor que o de um protesto simbólico e de uma descarga de tendências negativas" (Langer, 1986, p. 200).

Nesse sentido, as náuseas e vômitos podem ser vistas como formas de dissociar e diferenciar o bom e o mau dentro de si, expulsando o mau para ficar com o bom, o filho. Porém, em situações de aborto e prematuridade, o filho pode ser vivido, inconscientemente, como objeto hostil e, muitas gestantes podem não conseguir fazer o enfrentamento positivo de suas fantasias persecutórias e, com o intuito de aliviar a tensão interna, "expulsar o filho" como sendo mau e perseguidor dentro delas.

Maldonado (1981) cita que em alguns casos há franca rejeição por parte da gestante. As fantasias de aborto são provocadas por sensações do feto ainda não estar preso ao útero. Os comportamentos propositais ou acidentais como tombos, fumar, beber excessivamente remetem ao desejo de abortar, porém este desejo muitas vezes vem disfarçado por mecanismo de formação reativa, desencadeado por reações de muita cautela, autoproteção exagerada, evitando por vezes até a relação sexual.

Além desses comportamentos, a gestante pode recorrer a reações defensivas maníacas, imbuindo-se de tarefas intensas ou necessitando manter toda a família sempre à disposição. Soifer (1980) coloca que nesses casos, geralmente elas apresentam distúrbios somáticos como hiper ou hipotensão, varizes, insônia, bulimia, aumento de peso exagerado. Através do masoquismo e de fantasias de expiação, esses padecimentos físicos são também expressão de vivências terroríficas intensas atreladas às suas fantasias de origem infantil.

Freud (1976) esclarece que os instintos de morte podem estar em atuação nos sujeitos de algumas maneiras, uma delas seria a de que parte dos instintos é desviada para o mundo externo sob a forma de agressividade. Expulsar o filho, como vivência terrorífica, poderia ser interpretada como uma forma de expulsão dessa hostilidade, de exteriorização da agressividade.

Segundo preceitos Kleinianos (1982) as fantasias iniciais da gestação podem se referir a um sentimento de culpa da gestante de haver roubado a criança de sua mãe, de invejarlhe a capacidade de criar, de gerar e, ao mesmo tempo, um temor pela retaliação. Engravidar, gestar, se torna extremamente perigoso, pois a mulher estará tomando o lugar da sua mãe e ao mesmo tempo expondo a ela seu ódio. Abrigar o pênis, o sêmen, o feto dentro da gestante significa roubar algo que pertence à mãe, significa ganhar e triunfar sobre ela. Devido a isso há o perigo de castigo e destruição. Negar tudo (esconder dos familiares e de si mesmas) ou ainda desprender-se de uma gravidez roubada (aborto) é, por vezes, a forma de salvação e alívio frente a essas fantasias persecutórias. Um livrar-se de algo angustiante e destruidor que ela leva dentro de si. (Langer, 1986, p.198). Ainda referindo-se a fantasias inconscientes da gestante com relação à própria mãe, Langer, (1986) afirma que a mulher experimenta a gravidez como uma trama perigosa feita pela sua mãe e a própria gravidez converte-se também em castigo. A isto, a grávida reage com tentativas latentes de abortar, seguidas por um intenso sentimento de culpa (Langer, 1986).

A partir dos quarto mês, Soifer (1980) refere que, no geral, se torna possível a percepção dos movimentos fetais, sendo que há uma variação de percepção de movimentos iniciais que pode chegar até o sétimo mês. Essas percepções em diferentes meses também teria uma relação emocional atrelada ao desejo ou não pelo bebê.

As fantasias terroríficas desse momento de percepção de movimentos fetais aludem a movimentos agressivos (pontapés, chutes). Nesse caso, o mecanismo existente é o da projeção, uma imagem terrorífica é transferida ao feto, identificando-se a gestante com ele. O bebê é sentido como perigoso através de seus movimentos agressivos, sádicos ameaçando causar severos danos à mãe. Essa projeção remete aos impulsos em relação à própria mãe grávida (Soifer, 1980).

A partir do sexto mês gestacional, onde as mulheres tendem a sentir com maior intensidade as contrações uterinas, há uma reemergência das fantasias acima, porém nesse momento destaca-se o retraimento narcisista. Já a partir do sétimo mês de gestação com a movimentação fetal rumo ao canal do parto, as crises de ansiedade giram em torno das fantasias de esvaziamento. Nesse momento, as ansiedades podem também desencadear processos somáticos como hipertensão, hiperemeses, diarréias, constipação, aumento de peso, cãimbras, podendo evoluir para o parto prematuro. A prematuridade tem relação com as crises de ansiedade a níveis insustentáveis, com a predominância do instinto de morte (Soifer, 1980).

Para Maldonado (1992) a dificuldade de levar a gestação a termo remete a uma falta de holding na relação da gestante com a própria mãe, ou seja, ao não se sentir sustentada, a mulher sente dificuldade de sustentar e carregar dentro de si um novo ser. A sensação precoce de vazio, insatisfação e não preenchimento das necessidades básicas da relação se faz presente, geralmente na alusão a fantasias de um bebê voraz, sempre capaz de esvaziar as reservas da mãe.

Próximo aos nove meses, o maior temor da gestante é com relação à morte. A ansiedade desencadeada por essa fantasia reporta-se ao narcisismo infantil, ao pensamento mágico e a onipotência de ideias como forma de eliminação do estado de espera e incerteza (Maldonado, 1992).

É importante salientar que os sintomas podem ser vistos como formas da mente elaborar as vivências que lhe são desagradáveis. Esse ato desesperado tem o único objetivo de dar fim a fantasias terroríficas vivenciadas pela gestante. Não conseguindo elaborar essas questões mentalmente, no plano simbólico, a pessoa, inconscientemente, se utilizaria de sintomas e do ato real de não poder segurar a gestação na tentativa de elaboração concreta de suas questões internas.

\section{Considerações Finais}

Como se pode verificar, as situações de aborto e de partos prematuros podem ser contempladas por uma perspectiva psicológica de importância ímpar. Os fatores psíquicos permeiam as relações entre os seres humanos 
desde a sua mais tenra concepção, sendo que a sustentação de uma vida dependerá do quanto uma relação pode produzir de afeto, amor para suplantar as fantasias destrutivas, contrárias a essa ligação afetiva.

Segundo Freud (1974), os instintos destrutivos se manifestariam sob a forma de agressão, de extermínio, no intuito inato de conviver com essa hostilidade que tem de ser expressa e direcionada de alguma maneira. No caso explorado neste trabalho, o caminho encontrado (inconscientemente) pelas gestantes, é a exteriorização dessa agressividade (dirigida contra o filho - aborto), porém também uma parte dos instintos é direcionada ao próprio self, já que a agressão é feita também contra a própria pessoa.

Vê-se sob a ótica Kleiniana, ou seja, sob a ótica das relações objetais que o instinto de morte se expressa também sob a forma de insustentabilidade da vida (ser mãe, ter filhos, conseguir gerá-los ou sustentá-los no ventre). O desejo inconsciente de morte da gestante com relação à vida que não pode sustentar faz alusão a possível fragilidade egóica desenvolvida nos primórdios de sua infância, nas relações com suas figuras parentais. Assim, os maus objetos internalizados, resultantes de formações psíquicas inatas e disposições ambientais preponderariam, levando o indivíduo a ter dificuldades para gerar vidas ou para sustentá-las, uma vez que seus impulsos destrutivos, protagonizados pela ansiedade persecutória exacerbada, dominam sua vida psíquica.

A não ocupação de um espaço materno pode ter origem nos anseios do lugar de filha que ainda estão por desejar. Assim, competindo com as necessidades do filho a ser gerado, as suas necessidades preponderam uma vez que não pode abdicar da posição de filha e há, portanto que se fazer uma "escolha". Freud (1974) coloca que o medo de morrer pode ser derivado do fato do ego abandonar sua catexia libidinal narcísica. Visto dessa forma, não ocupar esse lugar materno seria uma forma de defesa egóica contra os impulsos destrutivos a ele dirigidos. Destinados a seguir um caminho, os impulsos são exteriorizados, resultando na expulsão.

Em "Sobre o narcisismo: uma introdução" Freud (1974) nos faz observar que o narcisismo seria um complemento libidinal do egoísmo do instinto de autopreservação. $\mathrm{O}$ processo do narcisismo seria $\mathrm{o}$ afastamento da libido do mundo externo e o direcionamento para o próprio ego. Cita que libido objetal e libido do ego seriam proporcionalmente inversas. Quanto mais uma é empregada, mais a outra se esvazia.

Retomando a insustentabilidade da vida pelas gestantes, pode-se pensar que o olhar altruísta é extremamente prejudicado, pois suas satisfações narcísicas não foram repletas em suas necessidades mais emergentes em algum momento precedente de sua história. A prioridade então é focada no desejo do desejante (ego narcísico) e talvez o desejo não seja nem pela morte do outro, mas pela preservação de sua própria vida. (Freire \&Chatelard, 2009; Freud, 1974).

Preservar a própria vida seria afastar de si a angústia persecutória e consequentemente o temor inconsciente de aniquilamento, como conceituou Klein (1981). Para o maduro enfrentamento dessa ansiedade frente à morte (impulsos destrutivos) o indivíduo haveria de ter bons recursos egóicos (ego maduro), suportando as fantasias destrutivas, sem dirigi-los maciçamente ao exterior. Quando se trata de recursos egóicos frágeis, o indivíduo se utiliza de recursos mais primitivos, dirigindo sua agressividade ao exterior, afastando-o de seu ego e consequentemente afastando a possibilidade de seu aniquilamento, de sua morte psíquica.

Longe de finalizar tais questionamentos, e com o intuito de maior reflexão e aprofundamento no tema de interesse, esse trabalho é finalizado com uma frase de Freud do mesmo texto citado acima. "Um egoísmo forte constitui uma proteção contra o adoecer, mas, num último recurso, devemos começar a amar a fim de não adoecermos, e estamos destinados a cair doente se, em consequência da frustração, formos incapazes de amar" (Freud, 1974, p. 101).

\section{Referências}

Ariés, P. (1981). História social da criança e da família. Rio de Janeiro: LTC.

Baranger, W. (1981). Posição e objeto na obra de Melanie Klein. Porto Alegre: Artes Médicas.

Badinter, E. (1987). O mito do amor materno. Rio de Janeiro: Nova Fronteira.

Gesteira, S. M. A., Barbosa, V. L., \& Endo, P. C. (2006). O luto no processo de aborto provocado. Revista Acta Paulista de Enfermagem, 19 (4), 462-67.

Cunha, F., \& Machado, R. (1988). A relação médico-gestantefamília nas situações de malformação congênita e de morte fetal. Revista Cientifica: Maternidade, Infância e Ginecologia, 8 (2), 35-38.

Anderson, R. (1994). Conferências clinicas sobre Klein e Bion. Rio de Janeiro: Imago.

Ferrari, A.G., Piccinini, C.A., \& Lopes, R.S. (2006). O narcisismo no contexto da maternidade: algumas evidências empíricas. Psico, 37(3), 271-278.

Freire, T.C.G., \& Chatelard, D.S. (2009). O aborto é uma dor narcísica irreparável? Revista Mal-Estar e Subjetividade, 9 (3), 1007-1022.

Freud, S (1974). Sobre o narcisismo: uma introdução. In: Edição standard brasileira das obras psicológicas completas de Sigmund Freud (Vol. 14, pp. 89-119). Rio de Janeiro: Imago. (Texto original publicado em 1914).

Freud, S (1974). O mal-estar na civilização. In: Edição standard brasileira das obras psicológicas completas de Sigmund Freud (Vol. 21, pp. 81-171). Rio de Janeiro: Imago. (Texto original publicado em 1930).

Freud, S (1976). Determinismo, crença no acaso e superstição: alguns pontos de vista. In: Edição standard brasileira das obras psicológicas completas de Sigmund Freud (Vol. 6, pp.287-332). Rio de Janeiro: Imago. (Texto original publicado em 1901).

Freud, S. (1976). O ego e o id. In: Edição standard brasileira das obras psicológicas completas de Sigmund Freud (Vol. 19, pp. 23-76). Rio de Janeiro: Imago. (Texto original publicado em 1923).

Gaiva, M. A. M., \& Ferriani, M. G. C. (2001). Prematuridade: Vivências de crianças e familiares. Acta Paulista de Enfermagem, 14 (1), 17-27.

Klein, M.(1982). Melanie Klein: psicologia. São Paulo: Ática.

Klein, M. (1991). Inveja e gratidão e outros trabalhos. In: Obras completas de Melanie Klein (Vol. 3). Rio de Janeiro: Imago.

Klein, M. (1996). Amor, culpa e reparação e outros trabalhos. In: Obras completas de Melanie Klein (Vol. 1). Rio de Janeiro: Imago.

Langer, M.(1986). Maternidade e sexo: estudo psicanalitico e psicossomático (2a ed.). Porto Alegre: Artes Médicas.

Lopes, R.C.S., Prochnow, L.P., \& Piccinini, C.A. (2010). A relação da mãe com suas figuras de apoio femininas e os sentimentos em relação à maternidade. Psicologia em Estudo, 15 (2), 295-304

Maldonado, M. T. P.(1981). Psicologia da gravidez, parto $e$ puerpério (4a ed.). Petrópolis: Vozes. 
Maldonado, M. T. P.(1985). Psicologia da gravidez, parto e puerpério (7a ed.). Petrópolis: Vozes.

Maldonado, M. T. (1989). Maternidade e paternidade. Petrópolis: Vozes.

Maldonado, M. T. (1992). Psicossomática e obstetrícia. In: Mello Filho, J. (Org.). Psicossomática hoje (pp. 208-14). Porto Alegre: Artes Médicas.

Maldonado, M. T. (2000). Psicologia da gravidez. São Paulo: Saraiva.

Moura, S. M. S. R., \& Araújo, M. F. (2004). A maternidade na história e a história dos cuidados maternos. Revista Psicologia: Ciência e Profissão, 24 (1), 44-55.

Piccinini, C. A., Gomes, A. G., Moreira, L. E., \& Lopes, R. S. (2004). Expectativas e sentimentos da gestante em relação ao seu bebê. Psicologia: Teoria e Pesquisa, 20 (3), 223-32.

Piccinini, C. A., Gomes, A.G., Nardi, T., \& Lopes, R. S. (2008). Gestação e a constituição da maternidade. Psicologia em Estudo, 13 (1), 63-72.

Quayle, J. M. B. R. (1991). Aspectos emocionais em perdas gestacionais. Revista de Psicologia Hospitalar, 1 (2), 52-5.

Scavone, L. (2001). Maternidade: transformações na família e nas relações de gênero. Interface: Comunicação, Saúde e Educação, 5 (8), 47-60.

Silveira, E. F., \& Procianoy, N. J. T. (1996). Desejo x medo de ter um bebê: a propósito de um caso clínico. Revista de Psiquiatria, $18(3), 361-66$

Soifer, R. (1980). Psicologia da gravidez, parto e puerpério. Porto Alegre: Artes Médicas.

Stellin, R. M. R., Monteiro, C. F. A., Albuquerque, R.A., \& Marques, C. M. X. C. (2011) Processos de construção de maternagem. Feminilidade e maternagem: recursos psíquicos para o exercício da maternagem em suas singularidades. Estilos da Clínica, 16 (1), 170-185. Campus.

Zalcberg, M.(2003). A relação mãe e filha. Rio de Janeiro:

Recebido: 23/08/2012

Última revisão: 08/05/2014

Aceite final: 23/05/2014

Sobre os autores:

Mychele Capellini Moris Taguchi - Psicóloga Clínica. Psicóloga na Prefeitura Municipal de Indaiatuba. Aprimoramento em Psicologia Hospitalar pela Faculdade de Medicina de Marília (FAMEMA).

Danielle Abdel Massih Pio - Mestre em Ginecologia, Obstetrícia e Mastologia. Doutoranda pelo Programa de PósGraduação em Saúde Coletiva, Unesp/Botucatu. Supervisora do Programa de Aprimoramento Profissional em Psicologia Hospitalar da Faculdade de Medicina de Marília (FAMEMA). Assistente de Ensino na FAMEMA. 